\title{
Factors Influencing the Success of a Market Based Conservation Initiative to Promote Rural Land-use Compatibility
}

\author{
John M. Diaz ${ }^{1, *}$, Robert E. Bardon², Dennis Hazel², Jackie Bruce ${ }^{3}$, \\ K.S.U Jayaratne ${ }^{3}$, Anne-Lise Velez ${ }^{4}$

\begin{abstract}
${ }^{1}$ Department of Agricultural Education and Communication, University of Florida, United States ${ }^{3}$ College of Agricultural and Life Sciences, North Carolina State University, United States

${ }^{4}$ Department of Agricultural and Human Sciences, North Carolina State University, United States
\end{abstract} \\ ${ }^{2}$ Department of Forestry and Environmental Resources, North Carolina State University, United States
}

Copyright $(2017$ by authors, all rights reserved. Authors agree that this article remains permanently open access under the terms of the Creative Commons Attribution License 4.0 International License

\begin{abstract}
Encroachment of incompatible land uses increasingly threatens military training across the country. In many states, military training grounds are part of the rural landscape resulting in significant interest from military leadership in the maintenance and enhancement of land uses that are compatible with training operations. In the southeast, a vast majority of the rural landscape is under private ownership increasing the needs for policies that address the interests of landowners and provide meaningful incentives for maintaining land-use compatibility. Market-based conservation strategies have the potential to provide an effective means for conserving large landscapes used for military training. This issue is particularly salient in North Carolina that has an extensive military training footprint. We conducted a case study to evaluate a cross-sector partnership in the state that collaboratively developed a Market-Based Conservation Initiative Pilot to promote land use compatibility by engaging private landowners in performance-based contracts. This study determined the factors that influenced pilot project outcomes and lessons learned when developing market-based strategies that integrate military interests. Data analysis identifies five key factors that are 1) military funding authority to establish agreements, 2) development of landowner trust and program credibility, 3) military understanding the purpose and associated risks of a pilot program, 4) military perception of rural landownership patterns, and 5) institutional mandates of the Navy.
\end{abstract}

Keywords Rural Landscapes, Private Landowners, Land-Use Compatibility, Conservation, Working Lands, Military Training

\section{Introduction}

The United States military maintains combat readiness through intensive training on the ground, in the air, and at sea. To achieve this purpose, the military relies on designated bases and training ranges. Critically important off-base air and land corridors that connect military bases and airfields with remote training ranges and allow access to key air training areas and routes supplement these designated areas [7]. Incompatible land uses in areas adjacent to military-controlled training areas negatively affect military readiness by restricting the military's ability to recreate realistic operational conditions [7]. A significant characteristic that renders a particular land use in a neighboring jurisdiction incompatible with military training is the routine presence of non-involved civilians too near or under military training and testing activities [7]. Compatible land use includes agricultural production, forestry, natural areas, or other uses that limit the construction of buildings and concentrated development. Residential and commercial land use can be less compatible, as conversions of these lands to such uses often result in higher population densities, tall structures, or other factors that impede realistic military training in the area.

As policy makers believe that market-based approaches will better achieve conservation goals by making conservation financially attractive to multiple sectors [10], this approach provides a potential solution for dealing with land-use and conservation conflicts between those administering military lands and non-military neighboring jurisdictions. The complexity and scale of issues associated with land use patterns emphasizes the need for a strategic landscape-scale conservation approach $[14,26]$. The concept of landscape-scale conservation is typically encompasses three criteria: 
"(1) multijurisdictional-the issues being addressed cut across political and jurisdictional boundaries; (2) multipurpose-they address a mix of related issues, including but not limited to environment, economy, and community; and (3) multistakeholder ${ }^{2}$ they include public, private, and nongovernmental actors." (McKinney, Scarleet, \& Kemis, 2010, p. 4).

The process of achieving landscape-scale conservation requires regional collaboration to address effective coordination and cross-jurisdictional complexities that require a variety of approaches tailored to fit the scope and nature of the particular issues $[5,13]$. As a result, market-based solutions to natural resource challenges are emerging as new tools for public and private entities to promote wise land use and working lands conservation at a landscape-scale while also seeking improvements in air, soil and water quality [17].

Market-oriented strategies to conservation generally provide flexibility to undertake actions related to natural-resource and environmental issues at a lower cost than traditional command and control approaches [17]. One such strategy is the reverse auction process where landowners bid for contracts that stipulate the provision of certain service levels or associated management actions, and provide monthly payments to displace costs or potential income lost $[6,8]$. This holds promise in areas of Military Training Routes (MTRs) because it can increase buy-in from surrounding landowners to maintain compatible land uses through a financial incentive driven by landowner interests and avoids zoning enforcement mechanisms by related jurisdictions.

Utilizing a market-based strategy for conservation in itself is not a novel approach but the level of complexity increases when these strategies integrate the military as a collaborative partner and leverage military investment. While the evaluation of market-based conservation approaches exists within the literature, there has been not any evaluation study of such an approach that considers land use in a military context and brings together multiple sectors. We conducted this evaluation study to fill this knowledge gap and present findings from a qualitative case study on the experience in a North Carolina Market-Based Conservation Initiative (MBCI) pilot project involving military and civilian partners. The aim of this case study is to better understand the key factors that influence market-based strategies in this context that can be used for those agencies and organizations that seek to involve the military or capitalize on available military funding in landscape-scale, market-based conservation efforts.

\subsection{Military Land Use in North Carolina}

North Carolina is a rapidly urbanizing state. It is the $9^{\text {th }}$ most populated state in the nation and by 2030 it is projected to rise to the $7^{\text {th }}$ largest, with 12.2 million people [25]. The military in North Carolina is the second largest economic sector in the state, just behind agriculture [20]. North Carolina has the third largest military population in the nation, home to the largest army installation and the world's largest amphibious training complex [18]. North Carolina leadership has a vested interest in the sustainability of rural landscapes that contribute approximately $\$ 100$ billion to the state's economy and provides irreplaceable ecosystem services that promote environmental quality [7].

\section{Literature Review}

Empirical research provides a basis for initial expectations surrounding factors that may be important considerations for market-based strategies involving military priority areas based on the evaluation of similar programs. Through a comprehensive evaluation of various market-based strategies, Pirard [22] identified two emblematic Payments for Ecosystem Services (PES) cases $[21,23]$ that focused on land-use and land-use compatibility. Each case provides an example of a government agency providing payments to landowners according to their land-uses and willingness to adopt conservation practices.

Perrot-Maitre [21] analyzed the PES program developed and implemented by Vittel in northeastern France. The study examined the methodology used by Vittel, and the ten-year process that was necessary to transform conflict into a successful partnership [21]. The main conclusion was that establishing a PES program is a very complex undertaking that requires the consideration of scientific but also social, economic, political, institutional, and power relationships [21]. Scientific and economic research was only introduced later after a "dialogue had been successfully established between Vittel and the farmers, compatibility between farmers' and Vittel's objectives had been demonstrated, and the idea of a mutually beneficial partnership accepted" [21, p.6].

According to Perrot-Maitre [21], the ability to maintain farmers' income level at all times and finance all technological changes was an important element of success, but primary reasons for the program's success were not financial. Trust-building through the creation of an intermediary institution that was locally based and led by a program champion sympathetic to the farmers' cause was critical to program success [21]. Perrot-Maitre [21] also found that the ability to link incentives to land tenure and debt cycle issues and to substitute the old technical and social support networks with new ones, were all fundamental conditions of success.

Perrot-Maitre [21] analysis shows that estimating costs and benefits of PES is not always possible. "Not all information is public knowledge, and costs are not broken down in a way that allows the separation of costs associated with the PES scheme from others" [21, p. 5]. Perrot-Maitre [21] explains that the Vittel experience is most likely to be replicable in places where land cannot be purchased and set aside for conservation, where the risk to business is high 
while the link between ecosystem health and farming practices is well understood, and expected benefits are sufficiently high to justify the investment. In North Carolina, the contextual linkages to the aforementioned case provide a relevant comparative case for this study.

Sanchez-Azofeifa et al. [23] evaluated the intention, implementation, and impact of Costa Rica's PES program. The program provided payments to private landowners who own land in forested areas in recognition of the ecosystem services their land provided [23]. This study demonstrated that PES contracts contributed little, if any, to the area's rate of deforestation with a negative correlation between the level of PES contracts and previous forest clearing [23]. Sanchez-Azofeifa et al. [23] believe it could have resulted from a policy design in which the PES contracts were fixed across space - each of the locations in the country is assumed to provide the same services and is offered the same level of payment per hectare- and enrollment was voluntary. This study set the stage for the understanding of dynamic conservation markets where landowner willingness and payment demands should be evaluated across the urban/rural gradient to identify a robust conservation market.

Sanchez-Azofeifa et al. [23] asserted that the prioritizing location of the first phase of PES contracts is important to consider as well. They explained that given considerable agency expertise in Costa Rica, and good local data, the PES program could have targeted threatened species so the impact could be greater than it initially appeared to be [23]. Yet because landowners chose whether to participate, lower profitability lands could dominate the program and a large fraction of payments could go to those who would have kept their lands in forest regardless of payments due to low opportunity costs $[19,23,24]$. This dynamic emphasizes the need to develop PES markets through multiple phases to ensure that the program influences land-use by changing the behavior of landowners who may not be as inclined to maintain their current land-use practices [23].

The evaluation of military land-use partnerships and initiatives by Lachman, Wong and Resetar [11] provide insights into specific issues that may arise due to military involvement that require consideration when developing a market-based conservation program. Findings show that the military places too much emphasis on cost efficiency issues at the expense of program effectiveness. Military programs that typically fund these efforts over-emphasize partners' provision of funds for conservation buffering. Lachman et al. [11] conclude it an unrealistic expectation for all buffering projects to have partners who can match or even come close to matching military funds.

Lachman et al. [11] explain that it is important to have a partnership that focuses on joint collaboration rather than on the best real estate deal for the military. Over-emphasis on fair market value defined by the Department of Defense (DoD) appraisal process has caused effectiveness problems, such squandering the potential to develop conservation agreements with landowners in priority areas [11]. Given that conservation buffering benefits the installation in ways that are not explicitly monetized as part of the land use agreements, and the evidence shows that the military saves money by completing buffering deals as early as possible, the program should not focus so much on such cost efficiency issues [11]. The Office of the Secretary of Defense (OSD) and the Services need to allow some flexibility in these issues because of the long-term benefits and eventual cost savings to the military.

Lachman et al. [11] concluded that the military's process for developing, approving, and completing deals has room for improvement. The military process, particularly the Navy and United States Marine Corps (USMC) process takes too long to develop, assess, approve, and fund property deals [11]. Since it can be difficult to engage landowners without funding in hand, "such processes need to be streamlined and other flexibility needs to be built into the system to enable the military to respond faster to real estate opportunities" [11, p. xxi].

The final consideration outlined by Lachman et al. [11] is that military-based programs tend to experience significant issues of distrust among landowners in relation to historical land takings to create and/or expand an installation [11]. Rural landowners typically do not trust programs or partnerships that involve the military [11], which creates a significant obstacle for a market-based conservation program that is predicated on voluntary landowner participation. While Lachman et al. [11] provide some meaningful considerations for military programs and partnerships in areas immediately surrounding an installation or base, there is a need to evaluate how to most effectively develop large landscape, market-based conservation initiatives. We believe that increased understanding of factors influencing program success will help to inform the development and implementation of future efforts that seek to engage landowners in conservation agreements that restrict land use practices to maintain land compatibility with military training operations, increasing chances of success.

\section{Methods}

Using an intrinsic case study design [27], we explored partnership documents as well as partner and key stakeholder perceptions to understand what key factors influenced the outcomes of the MBCI pilot. We identified the initial nine study participants using purposive sampling based on their influence on overall partnership and programmatic decision-making. We identified an additional four participants using a snowball sampling approach, where each initial participant identified additional subjects to interview based on their engagement and influence within MBCI. Sampling ended at thirteen participants when data saturation was achieved, meaning no new themes 
emerged in data collection and analysis.

Semi-structured, in-person interviews were conducted with each participant, and were recorded, transcribed, and coded. Interviews ranged from thirty minutes to two hours depending on participant's responses and the need to probe specific responses for additional clarity. The open-ended interview questions focused on human and policy dimensions of MBCI and use Melaville and Blank's [15] evaluative framework for cross-sectoral partnerships as a basis.

Interviewers engaged in continuous analysis and categorization as data were collected, using the constant comparative method with categories derived directly from the data, rather than an existing conceptual or theoretical framework [2]. As part of the constant comparative method, we used content analysis during data triangulation to analyze organizational documents (i.e. meeting notes, planning documents and correspondence materials). The categories that emerged added to a complete and holistic view of the MBCI pilot. Select quotes from key informants appear in the results section using participant identifications (for example R1) for interview data and document identifications (for example doc1) to identify specific data points.

\subsection{Case Context: North Carolina Market-Based Conservation Initiative Pilot Project}

A cross-sectoral partnership in North Carolina, the North Carolina Sentinel Landscape Partnership, came together to address issues of adjacent landowners' land-use compatibility with military training through an MBCI pilot project. This cross sector partnership consisting of government, nonprofit, and private stakeholders includes key leadership that represents the interests of working lands (agriculture and forestry), natural resource conservation, and military training. The involvement of the military included leadership from both the Navy and Marine Corps was regarded as the predominant funders of the program. The partnership formed three committees (economics, science and policy) leveraging the expertise of the partners to inform the development of the pilot structure. MBCI was originally developed to utilize the funding authority of the SIKES Act (16 USC 670a-670o, 74 Stat. 1052) but was ultimately implemented under the authority of 2684a (10 U.S. Code $\S 2684 a$ - Agreements to limit encroachments and other constraints on military training, testing, and operations). The partnership used The Cooperative Ecosystems Studies Unit (CESU) as the vehicle to distribute military funds to the partners for project development and implementation.

The lead administrator for the implementation of the pilot project was the North Carolina Foundation for Soil and Water Conservation, a nonprofit organization that through the local soil and water conservation districts in collaboration with the partnership. The project area encompassed 18 counties in Eastern North Carolina that reside under a MTR that is utilized by all military services in the state. The pilot used a reverse auction bidding process, allowing landowners to decide the monetary value need from them to enter into a contract that places limited restriction on their land while also determining the longest acceptable period at a specific bid range. It was designed to provide landowners the opportunity to submit multiple bids over time that would inform and be informed by the development of a conservation market. Unfortunately, due to specific terms related to military involvement, the pilot was cut short only allowing for a bidding iteration.

\subsection{Trustworthiness}

As with all case studies, it is necessary to establish trustworthiness. Here, trustworthiness is established using tenets of credibility, transferability, dependability and confirmability $[1-4,9,12,16]$.

\subsubsection{Credibility}

Credibility requires prolonged engagement [12], persistent observation [12], data triangulation [1], member checks $[3,12]$, peer debriefing $[3,4]$, and negative case analysis [12]. The researchers engaged with the partnership for approximately three years, which allowed for the development of a holistic and comprehensive understanding of the case and the development of trust among study participants. Over the three years of engagement, the researchers had the opportunity to observe the participants by attending over twenty in-person partnership meetings, over thirty partnership conference calls, four partnership-related landowner workshops, and three other miscellaneous partnership events resulting in hundreds of hours of engagement and observation.

Researchers analyzed documents and triangulated those against data from the semi-structured interview to gain a deeper understanding of the findings that emerged [1]. After interview transcription, the researchers provided the participants transcripts of their interviews to check for accuracy. Participants were also able to review rough drafts of the researchers' work in order to correct or provide substitute language [3].

We used a team of peers to take part in the debriefing process based on their knowledge of the partnership, qualitative methods and partnership evaluation. This team included both internal and external members of the research project to provide varying perspectives to the process. After each step in the analysis process researchers created a memorandum for the team, updating them on the study process and data analysis. The peer debriefs team provided guidance throughout the process by suggesting revisions to categories and reviewing themes with the researchers. This feedback informed corrections by the researchers to the developing analysis.

To explore all exceptions that emerged during analysis 
through subsequent interviews and literature review, we used negative case analysis to account for the exception and confirm patterns emerging from the data. It was used as a measure to ensure that the research process was not pursuing interpretations of events that were not shared among multiple participants or presented in previous studies. This analysis provided overall direction for the presentation of study findings.

\subsubsection{Transferability}

In order to promote the readers ability to transfer the findings of the study to their own context (transferability), rich description of the insights and lessons learned accompany details about with the population of interest and study context. By developing this comprehensive view, the researcher facilitates the reader's ability to identify the commonalities and differences as it relates to their case and ultimately judge how the associated findings may transfer $[3,9]$.

\subsubsection{Dependability}

To ensure the dependability of the study, the research team constructed a dependability audit trail $[1,4]$ based on detailed notes taken throughout the study. This audit trail formed the basis for an inquiry audit that leveraged the input of external researchers to evaluate the researcher's ability to outline a process for replication. Each auditor received detailed notes that outlined the overall research process, the evolution of the process through analysis, and associated thoughts and decisions along the process.

\subsubsection{Confirmability}

To authenticate the confirmability of the study, the research team employed a closely related confirmability audit trail. The confirmability audit was conducted at the same time as the dependability audit, requiring the auditors to evaluate whether the data and interpretations made are supported by material in the audit trail, are internally coherent, and represent more than the researchers' biased perspective [12]. The audit trail provided details on data collection, category development, and decision-making throughout the inquiry [16]. The audit trail provided an organizational structure to understand the relationship between the conclusions, interpretations, and recommendations by clearly linking to the data sources themselves. To increase confirmability the researchers used multiple methods of triangulation (Lincoln \& Guba, 1985) including triangulation of sources and analyst triangulation to help facilitate a deeper understanding of the phenomenon of interest.

To help maintain objectivity, the researchers developed a reflexive journal that allowed them to track methodological decisions and study logistics as well as the researchers' own values and interests. Journal entries occurred before and after every interview as well as throughout the process to keep bias in check and keep the researchers on track. The researchers documented bias that related to personal experience and beliefs as well as experience with the partnership throughout the research process. Journaling allowed the researchers to review data and reflect on personal variables that could affect the interview and data collection process [12].

\section{Results and Discussion}

Data analysis indicates five key factors influenced the outcomes of the MBCI pilot in the context of military interests. The five factors are: 1) funding authority to establish agreements, (2) development of landowner trust and program credibility, 3) understanding the purpose and associated risks of a pilot program, 4) perception of rural landownership patterns, and 5) institutional mandates of the Navy. The factors are presented in order based on their level of influence perceived by the study participants. Below, we elucidate each factor. Direct quotes from the study participants provide insights from their perspective.

\subsection{Funding Authority and Landowner Agreements}

In this case, the factor that all participants identified as the most significant impediment for program success and a concern for future endeavors was the funding authority used to establish conservation agreements with landowners (doc2). All of the partners believe that this factor requires significant consideration for any market-based program that involves the military because the funding authority was leveraged as a result of military investment. The specific funding authority used for the pilot was U.S. Code $\S 2684 a$ (Agreements to limit encroachments and other constraints on military training, testing, and operations), that evokes a real estate transaction process for the establishment of conservation agreements. This represents a diversion from the program's original plan to use the funding authority 16 USC 670a-670o, 74 Stat. 1052, also known as the Sikes Act (doc2). A key partner involved with MBCI explained that "when all the dust settled [they] had shifted from the Sikes Act to another authority called 2684A [that] by the nature of that authority [evokes] the acquisition process [and] considers [conservation agreements] as a real estate acquisition (R6)."

Several partners that served on the steering committee for the initiative (R2, R3, R4, R6, R9, R11) explained that the funding authority excessively complicated "the process of due diligence, title searches, appraisals, [and] surveys (R6)." Those within the core leadership group (R3, R4, R6, R11) demonstrated frustration with the resulting issues as one partner asserted that "unless [the] project [is] setup under an authority that will let [the concept] work, it's not worth doing because the rules require you to incur transaction costs that are so high, you won't be able to justify the investment (R3)." One example that was provided by 
multiple partners (R1, R3, R4, R6) for this escalation of costs was the 60 year title search that was an associated Department of Defense (DoD) process requirement for 2684a. MBCI was incurring costs for "various lawyers involved in parcel review process [in addition to] the cost for [the Navy's] real estate staff [that] was running higher than the actual contract an individual landowner would receive (R6)."

The funding authority not only resulted in a program that was not cost-effective but was also not timely in its establishment of contracts with landowners (doc3, doc4). All of the partners and key stakeholders identified significant issues related to the amount of time that elapsed between a landowner bid and an accepted application that they believe tarnished the program's reputation with landowners. A key partner in the core leadership group explained that "the flow of funding from Naval Facilities Engineering Command (NAVFAC) to the [initiative] and [then] to landowners [themselves] was unworkable (R3)." Records show that the MBCI program received its first set of bids in the spring of 2013 and the first contracts were not signed until the summer of 2015 (doc6).

These issues were observed in evaluations of similar efforts conducted by Lachman et al. [11] showing that the military's over emphasis on fair market value as defined by DoD's appraisal process causes effectiveness problems resulting in lost deals. Since it can be difficult to engage landowners in contracts, "such processes need to be streamlined and other flexibility needs to be built into the system to enable the military to respond faster to real-estate opportunities" [11, p. xxi]. The military sponsor of MBCI echoed this sentiment and explained that in order to make MBCI effective; it must "simplify the process to where it does not require the same level of attention as a real estate acquisition (R1)". Several partners (R1, R2, R3, R4, R5, R6, R9) believe that this can be accomplished by "pursu[ing] [MBCI] under a different authority (R9) [because] the land [acquisition] and contracts issues [are] specific [to the] authority for which [MBCI] was pursued (R9)." The program initiative lead (R4) among others (R3, R5, R6, R9) believes that the Sikes Act provides more of a compatible authority for a market based program because it offers "more flexibility and is natural resources focused (R4)." While the Sikes Act has been leveraged for environmental work inside the bases, there remains a level of uncertainty for its applicability to address natural resources issues outside the base.

\subsection{Landowner Trust and Program Credibility}

While the funding authority represents the most significant impediment for MBCI, the NC Sentinel Landscape Partnership's ability to achieve landowner trust and increase program credibility alternately represents a factor that provides a significant advantage. The military partners (R1, R2) understood that they faced significant issues of distrust and explained that it was critical to have leaders that were "trusted going into the community [because] the military did not have that trust (R1)." This sentiment was shared among all partners, with one of the program leads explaining that the "[public perception of the military] was part of the reason they looked into an avenue to partner with organizations that already had established relationships with landowners (R4)."

Several partners (R1, R2, R3, R4, R5, R6, R10, R11) cited landowner workshops held by the local soil and water conservation districts as an effective medium for engaging landowners and local leaders in meaningful discussions about "protecting rural lands and increasing revenue for rural economies (R10)." These discussions were identified by multiple partners (R1, R3, R4, R6, R11) as an effective means of reputation management and served as an important "precursor to the application and bidding process (R3)."

To create a forum that would allow for meaningful discussion, MBCI solicited a recently retired and highly esteemed individual to lead the workshops. The partnership was able to access what one partner explained was "the gatekeeper to the community" that had rich and ongoing relationships with a large number of landowners because they "live in the community and are shopping at the same grocery stores (R6)." This resulted in a perception that the program included people that the landowners could relate with and in turn fostered trust among landowners, ultimately leading to increased program credibility. Several partners (R1, R3, R4, R7, R9, R10) agreed that by using the aforementioned approach it "automatically creates an environment of trust (R4)"that facilitated the engagement of everyone "from landowners to local governments (R5)" in various aspects of MBCI.

This case demonstrates how trust-building through an intermediary organization that is sympathetic to the needs of the landowners is critical to program success [21]. MBCI used trusted partners within the NC Sentinel Landscape Partnership as that organization to help with reputation management to overcome issues of trust. Existing relationships and increased levels of trust allowed MBCI to maintain the engagement of landowners throughout the long process and mitigate any potential ill-will towards the partnership. Leveraging the assistance of trusted members of the communities also helped to increase the program's reputation and credibility.

Extensive public outreach was a keystone in the progress of MBCI in educating local communities and landowners of the value added of the program as well as mitigate issues of trust [11. 21]. This case demonstrates how successful market-based programs need to develop dialogue between the landowners and program leadership so that cooperative learning can occur and the idea of a mutually beneficial partnership projects can be accepted [21]. Additionally, public outreach is an important tool to overcome landowner distrust towards the military and increase the program's 
social capital for sustainable and successful community collaboration.

\subsection{Purpose and Associated Risks}

Misunderstanding the purpose of a pilot and not accurately understanding its financial risk were two significant factors that contributed to the abbreviation of the pilot project. Purpose and associated risks are particularly important considerations in land use initiatives such as this especially when testing a new concept, approach or application. A misunderstanding of the purpose of the market-based conservation pilot as well as its associated risk was evident among the broader group of military stakeholders based on the feedback of program partners and key stakeholders.

The case of MBCI demonstrates the negative outcomes that can result from reframing or presenting a pilot project in a way that is not true to its goals in order to gain the support from military leadership. The hope of the initial steering committee that developed the MBCI pilot was to understand "how best to [protect the MTR] and further inform a discussion as to whether [MBCI] was the right tool to use (R4)." To make this determination, their initial intention was to "have a random sample[e] large enough to provide the data of the landowners' preferences in Eastern North Carolina (R2)." The core military partners (R1, R2) explained that while the overarching goal of the pilot was to "test a concept (R2)" in order to sell the initiative to the military they presented it as a "concrete program (R1)" that would provide protection to the MTR. The aforementioned disconnect was addressed during multiple conference calls with the internal group of partners and brought to the table during discussions with the Navy when initial considerations were made for termination of the pilot (doc1). Even though discussions were held, the aforementioned military partners felt that the partnership "didn't convey sufficiently, routinely enough, and an understandable manner what the primary goal of the program was, because if that had been understood that question never would have not come up because that wasn't the intent of [MBCI], it was not to protect the MTR (R1)."

This case demonstrates the need to educate military stakeholders on the concept of market-based conservation and the intention of a program pilot. The MBCI pilot provides a valuable lesson learned in the need to avoid presenting the initial pilot as a concrete program with a visible footprint to attain the necessary support to develop and implement the initiative. The aforementioned misstep resulted in Navy leadership misunderstanding the purpose of the pilot and its associated risk that eventually compromised the sustained support needed for the success of the program. When presenting a market-based pilot project to the military, it is of increased necessity to better educate military stakeholders to the market-based approach, the idea of testing a concept, and the value of identifying a salient market through a pilot in order to minimize future costs.

As a result of misunderstanding the purpose of the pilot project, the military also misunderstood the associated level of financial risk that eventually led to its early termination (R1，R2，R3，R4，R5，R6, R7, R11, doc1). The military sponsor explained that from the side of the military "there is a general lack of understanding when you push out new [conservation] programs [that] there's a risk [of] failure (R1)." The program lead responsible for the initiative explained that "the military did not seem to have done any pre-calculation [of the financial risks] for them to deliver the pilot (R4)." Another partner intimately involved in the initiative added that "[the military] did not go into [the pilot] understanding what the cost was going to be [which was evident] when they presented the due diligence costs for a typical contract (R6)."

While there was the perception that misunderstanding financial risk was a shortfall due to military involvement, this issue has occurred in other PES programs. As we saw in Perrot-Maitre's [21] study, estimating costs and benefits of a payment for services approach is not always possible because "not all information is public knowledge, and costs are not broken down in a way that allows the separation of costs associated with the PES scheme from others" [21, p. 5]. This inability to accurately anticipate the programmatic costs resulted in a disconnection between the anticipated costs of due diligence and the elevated costs realized during the pilot.

\subsection{Rural Landownership Patterns}

The unique organizational characteristics of the Navy and their historic lack of engagement with local communities in Eastern North Carolina resulted in significant challenges for engaging in conservation agreements with private landowners across rural landscapes. Multiple partners identified the Navy's misperception of land ownership in Eastern North Carolina as a contributing factor towards negative outcomes of the MBCI (R1, R2, R3, R4, R5, R6, R7, R10). A key partner who regularly engaged with North Carolina landowners explained that the military's engagement and understanding of these landowners varies from "the different branches of the service (R7)" and the fact that the Navy is predominantly "in the middle of the ocean...they don't care about relationships (R7)." Another partner further explained that the Navy provides an "interesting comparison to those branches that deal more with the people on land (R9)" in regards to their understanding of the rural landowner context.

The Navy's lack of engagement and understanding of rural lands was cited by the partnership as a significant impediment towards the effective involvement of Navy leadership (doc5). A steering committee member echoed the 
aforementioned sentiment explaining that the "one thing that set the Navy back is they had not thought through what property ownership looks like in North Carolina (R3)." The perception was that the Navy could simply purchase a few tracts of land with large acreages that in turn would achieve their land conservation goals. The associated program initiative lead provided clarity on this dynamic, explaining that "[the Navy] didn't realize that there are many tracts of land out there that are 120 acres or 75 acres (R4)" that would require several contracts to achieve acreage conservation goals.

Several partners (R1, R3, R4, R5, R6, R8) identified this misperception or misunderstanding as a "major stumbling block for the Navy (R4)" because they did not understand "local landowners, the landscape, the tracts, and the size and the numbers that [the partnership was] dealing with (R4)." The partners identified that these misperceptions affected the implementation of MBCI because the associated military process requirements of the selected funding authority resulted in "restrictions on [landowners] not matching up with the realities of famers on the ground (R9)." A key stakeholder on the MBCI steering committee provided clarity on this issue explaining that "farmers [are] not necessarily having perfect land tenure records [but] the Navy need[s] that (R9)." The program initiative lead and others (R3, R5, R6, R8) believed that this disconnect was only further exacerbated by the use of "federal lawyers and real estate contract specialists (R4)" to manage the process on the Navy's side, who "don't know agriculture...don't know farming [and] don't know what landownership looks like in Eastern North Carolina. (R4)."

These results highlight the need for an additional measure to educate military stakeholders on the local context of implementation, specifically as it relates to the nature of landownership and trends. The Navy had significant misperceptions of land ownership in Eastern North Carolina with the belief that much of the rural land was in large land holdings owned by a few landowners. They mistakenly envisioned establishing purchase agreements with landowners of large thousand-acre properties in order to achieve their conservation goals. In contrast, land ownership in Eastern North Carolina does not follow that trend and in fact comprises many landowners with small acreages, with many under 100 acres in size. With an over-emphasis on cost-effectiveness, the Navy will continue to ignore small landowners and promote process restrictions that do not match with the reality of land ownership. Perrot-Maitre [21] found that the ability to link incentives to land tenure and debt cycle issues are fundamental conditions of successful market based solutions, which will continue to complicate military-based programs if not effectively addressed.

\subsection{Institutional Mandates of the Navy}

The MBCI pilot project was designed to provide landowners with the opportunity to submit multiple bids over time that would inform and be informed by the development of a conservation market. The pilot project was terminated early due to institutional mandates of the Navy to assume no financial risk and based on this, the partnership was unable to effectively test the market based concept and identify an acceptable market for landowners and the military (doc1). The program initiative lead explained that they couldn't "say that the market had an opportunity to work in terms of the bids because in some of the phases they only had one bid round [and] and are not going to be able to analyze [where the market exists] because [the pilot] was terminated (R4)." Quarterly meeting notes (doc2) show that the initiative's leadership felt that due to the early termination "questions still surround the bid floor, conservation drivers, limitation of development rights, and possibility of enhancing other ecosystem services."

Multiple bid rounds and phases were necessary to understand if the market-based mechanism would promote conservation among a broad range of landowners. An MBCI steering committee member explained that "this type of contract could potentially take some value from your farm if you wanted to sell it (R9)" and the program would need to consider "how much [of] these contracts were just going towards famers who would not have [sold] their land anyways (R9)." Several partners (R1, R2, R3, R4, R5, R6, R11) explained that in order to understand the market required to promote the necessary action among a range of landowners across the landscape, it would require multiple considerations that could be achieved by multiple bid iterations.

Additionally, the partnership felt that a true valuation of the airspace and the associated landscape was not possible due to the single bid iteration (R1, R3, R4, R6, R7, R8 R10, doc2). A key partner involved with MBCI explained that due to the "termination of the pilot and the lack of different bid rounds and the analysis [the military put] very little consideration into the difference in the value in Bertie County versus Johnston County on the edge of Raleigh (R6)." While Bertie County is a very rural county, Johnston County is on the urban fringe Wake County demonstrating the urban-rural gradient that exists in the program area. The program initiative lead provided additional clarity, reporting that part of the charge of the pilot was "to figure out what is the best value for the airspace for the property owners and the people using the airspace to keep the land under it in the compatible use (R4)."

Several partners (R3, R4, R5, R7, R9, R11) identified the Navy's strong desire to achieve a pre-determined bid range as a factor resulting in the exclusion of valuation analysis (assigning monetary values to land characteristics across the study area) as well as the realization of the necessity of multiple bid rounds. The program initiative lead explained that "[the Navy] basically stayed within their narrow sweet-spot (R4)" not recognizing that they may have to pay landowners more or less based on "different aspects of the 
property: where it is, how big it is, and other things like that (R4)." Another MBCI steering committee member explained "the military didn't accept [bids] that clearly fell out of the range [\$25/acre] of what they wanted to accept in terms of the market signal (R9)." Based on the events that occurred within MBCI, a steering committee member explained that "having a strong source of demand [from landowners] and kind of a clear signal [from the military regarding their desired market] is really important" but in the case of MBCI "it seemed like we had [a clear signal] and then we didn't (R9)." The military originally was willing to allow the landowners to drive the market but eventually developed their own market value of the land that, to help avoid financial risk became a significant criterion for selection.

Due to the abbreviation of the MBCI pilot, there were insufficient bidding iterations that compromised the program's ability to identify a salient market. MBCI simply had a bidding iteration in each county that prevented the program from understanding the composite value of the land across the MTR. Valuation requires significant data to determine the value to landowners to restrict development across the rural, suburban and rural gradient. These efforts typically require at least three iterations to identify the market, provide the data to inform future efforts, and promote the engagement of landowners separate from early adopters [23]. The inability to identify a salient market ultimately compromises the final goals of this type of approach in achieving conservation expectations at the lowest costs.

\section{Conclusion and Recommendations}

MBCI provides some valuable lessons learned and best management practices for consideration when developing a market-based conservation program or pilot project that intends to conserve rural landscapes used for military training. This case demonstrates that there are special nuances related to military involvement that present unique challenges for program leadership. Future endeavors must consider the important human and policy dimensions in the development and evaluation of relevant strategies as this type of initiative requires action among several stakeholder groups, across a large landscape $[5,13,15]$ Table 1 outlines our recommendations for action among key stakeholder groups based on the key lessons from this study and provides a great framework for various stakeholder groups to consider for the development of future efforts within a similar context.

While the factors discussed may manifest differently based on context, we believe that they will apply in some form across any military-based pilot initiative regardless of stakeholder involvement. As our recommendations indicate, education serves as an important policy tool to ensure the success of this type of initiative. This understanding is important as federal programs such as Sentinel Landscapes pursue tools to effectively engage private landowners to maintain rural land compatibility. Developing local solutions that have the potential to inform national efforts holds promise for the protection of an extensive military training network that is necessary for national defense.

Table 1. Lessons Learned by Stakeholder Group

\begin{tabular}{|c|c|c|}
\hline Factor & Action(s) & Stakeholder Group(s) \\
\hline Purpose and Associated Risks & $\begin{array}{c}\text { Educate military stakeholders on the purpose of a pilot, the } \\
\text { associated risks of testing a concept and potential benefits }\end{array}$ & Extension \\
\hline Rural Landownership Patterns & $\begin{array}{c}\text { Educate military stakeholders on the landownership patterns } \\
\text { in the project area so that process requirements align with } \\
\text { realities on the ground }\end{array}$ & $\begin{array}{c}\text { Extension, Agricultural and } \\
\text { conservation agencies and } \\
\text { organizations }\end{array}$ \\
\hline Institutional Mandates of the Navy & $\begin{array}{c}\text { Educate the Navy on the risk of a pilot and the need to allow } \\
\text { multiple bid iterations to identify a salient market that } \\
\text { provides financial flexibility }\end{array}$ & Extension \\
\hline $\begin{array}{c}\text { Funding Authority and Landowner } \\
\text { Agreements }\end{array}$ & $\begin{array}{c}\text { Pursue a market-based program that leverages another funding } \\
\text { authority (i.e SIKES Act) that will not incur the real estate } \\
\text { transaction process }\end{array}$ & Military or coordinating entity (i.e. \\
\hline $\begin{array}{c}\text { Landowner Trust and Program } \\
\text { Credibility }\end{array}$ & $\begin{array}{c}\text { Partner with organizations that are trusted among rural } \\
\text { landowners that have already existing relationships in local } \\
\text { communities }\end{array}$ & Military \\
\hline
\end{tabular}




\section{REFERENCES}

[1] Berg, B. L. Qualitative research methods (5th ed.). Pearson Education, Inc., Boston, 2004.

[2] Corbin, J., and Strauss, A. Grounded theory research: Procedures, canons, and evaluative criteria, Qualitative Sociology, Vol. 10, No. 1, 3-21, 1990.

[3] Creswell, J.W. Qualitative inquiry and research design: Choosing among five traditions, Sage Publications, Inc., Thousand Oaks, 1998.

[4] Dooley, K.E. Viewing agricultural education research through a qualitative lens, Journal of Agricultural Education, Vol. 48, No. 4, 32-42, 2007.

[5] Durant, R. F., Chun, Y. P., Kim, B., \& Lee, S. Toward a new governance paradigm for environmental and natural resources management in the 21 st Century?, Administration \& Society, Vol. 35, No. 6, 643-68, 2004.

[6] Eigenraam, M., Strappazzon, L., Lansdell, N., Ha, A., Beverly, C., Todd, J. EcoTender: auction for multiple environmental outcomes. National Action Plan for Salinity and Water Quality, National Market Based Instruments Pilot Program. Final project report. Australia Department of Primary Industries, Melbourne, 2006.

[7] Governor's Land Compability Task Force (GLCTF) report, North Carolina Digital Collections: North Carolina Department of Environment and Natural Resources, Online available from

http://cdm16062.contentdm.oclc.org/cdm/ref/collection/p160 62 coll9/id/22139

[8] Greenhalgh, S., Guiling, J., Selman, M., \& St. John, J. Paying for Environmental Performance: Using Reverse Auctions to Allocate Funding for Conservation. WRI Policy Note, vol. 3. World Resources Institute, Washington, D C., 2008.

[9] Krefting, L. Rigor in qualitative research: The assessment of trustworthiness, The American Journal of Occupational Therapy, Vol. 45, No. 3, 214-222, 1991.

[10] Kroeger, T., \& Casey, F. An assessment of market-based approaches to providing ecosystem services on agricultural lands, Ecological Economics, Vol. 64, No. 2, 321-332, 2007.

[11] Lachman, B. E., Wong, A., \& Resetar, S. A. The Thin Green Line: An Assessment of DoD's Readiness and Environmental Protection Initiative to Buffer Installation Encroachment (Vol. 612). Rand Corporation, Santa Monica, 2007.

[12] Lincoln, Y.S., \& Guba, E.G. Naturalistic inquiry, Newbury Park, CA: Sage Publications, Inc., Newbury Park, 1985.

[13] McKinney, M., \& Johnson, S. Working across boundaries:
People, nature, and regions, Lincoln Institute of Land Policy, Cambridge, 2009.

[14] McKinney, M., Scarlett, L., \& Kemis, D. Large Landscape Conservation: A Strategic Framework for Policy and Action, Lincoln Institute of Land Policy, Cambridge, 2010.

[15] Melaville, A.I. \& Blank, M.J. What It Takes: Structuring Interagency Partnerships to Connect Children and Families with Comprehensive Services, Education and Human Services Consortium, Washington, D.C., 1991.

[16] Merriam, S.B. Qualitative research: A guide to design and implementation, Jossey-Bass, San Francisco, 2009.

[17] National Association of Conservation Districts (NACD). Market Based Initiatives White Paper. Washington, D.C.: NACD, Online available from http://www.nacdnet.org/wp-content/uploads/2016/06/Marketbased-conservation-White-Paper.pdf

[18] NC Military Foundation. A Unique Military Presence, Online available at http://www.ncmilitary.org/content/unique-military-presence

[19] Newburn, D., Reed, S., Berck, P., \& Merenlender, A. Economics and Land-Use Change in Prioritizing Private Land Conservation, Conservation Biology, Vol. 19, No. 5, 1411-1420, 2005.

[20] Nienow, S., Harder, C., Cole, T., \& Lea, A. (2008). North Carolina's military footprint: current economic impacts and projects for 2013. North Carolina Department of Commerce. Raleigh, NC

[21] Perrot-Maitre, D. The Vittel payments for ecosystem services: a "perfect" PES case. International Institute for Environment and Development, London, 2006.

[22] Pirard, R. Market-based instruments for biodiversity and ecosystem services: A lexicon, Environmental Science \& Policy, Vol. 19, 59-68, 2012.

[23] Sancehz-Azofeifa, G.A., Pfaff, A., Robalino, J. A., \& Boomhower, J. P. Costa Rica's payment for environmental services program: intention, implementation, and impact. Conservation Biology, Vol. 21, No. 5, 1165-1173, 2007.

[24] Sierra, R., \& Russman, E. On the efficiency of environmental service payments: a forest conservation assessment in the Osa Peninsula, Costa Rica, Ecological Economics, Vol. 59, No. 1, 131-141, 2006.

[25] U.S. Census Bureau. Population Projections, Online available at https://www.census.gov/population/projections/

[26] Weber, E. P., Lovrich, N. P., \& Gaffney, M. J. Assessing collaborative capacity in a multidimensional world, Administration \& Society, Vol. 39, No. 2, 194-220, 2007.

[27] Yin, R. K. Case study research: Design and methods, Sage publications, Thousand Oaks, 2013. 